\title{
Twice daily tripotassium dicitrato bismuthate in the treatment of duodenal ulceration
}

\author{
David Hollanders
}

Department of Medicine, University Hospital of South Manchester, Manchester M20, UK.

\begin{abstract}
Summary: Fifty three patients with endoscopically proven duodenal ulceration have cooperated in a clinical trial to compare the ulcer healing effect of tripotassium dicitrato bismuthate (TDB) at standard dosage administered either twice or four times daily. No statistically significant difference has been found to exist between ulcer healing in the two groups at 4 weeks $(72 \%$ and $67 \%, P=0.944)$ or at 8 weeks $(92 \%$ and $81 \%, P=0.504$ ) and it is concluded that twice daily TDB maintains the effectiveness of the drug and has advantages for patient compliance.
\end{abstract}

\section{Introduction}

Tripotassium dicitrato bismuthate (TDB) in both liquid (Martin et al., 1981; Shreeve et al., 1983) and tablet form (Vantruppen et al., 1980; Moshal et al., 1981) has been shown to heal duodenal ulceration as effectively as cimetidine. However, while the trend for some other ulcer healing drugs, particularly the $\mathrm{H}_{2}$ antagonists, has been to move to a twice or single daily dose it is recommended by the manufacturers of TDB (Gist Brocades) that the drug be given four times daily. This increases inconvenience of use and interferes with patient compliance. The present single-blind study has been designed to compare TDB tablets given four times daily with a twice daily regime in the healing of duodenal ulcer.

\section{Patients and methods}

Fifty three patients were enrolled into the trial and assigned randomly to receive TDB chewable tablets one four times daily (QDS group) or two twice daily (BD group). Each tablet contained $120 \mathrm{mg}$ tripotassium dicitrato bismuthate. At the end of the study there had been seven withdrawals leaving 21 patients in the QDS group and 25 patients in the BD group for analysis. The groups were well matched for age, duration of ulcer disease, length of current relapse, smoking and drinking habits. No statistically significant difference ( $t$ test) for any of the parameters was found (Table I).

Before entry to the trial all patients had endos-

Correspondence: D. Hollanders, M.Sc., M.R.C.P. Accepted: 7 August 1985 copically proven duodenal ulceration, had given their informed consent and had used no ulcer healing or ulcerogenic drugs in the preceding 2 weeks. In all cases treatment commenced on the same day as the diagnostic endoscopy. Antacids of their choice were allowed as required and patients were asked not to change their drinking or smoking habits for the duration of the study. Patients specifically excluded were any who had previously undergone upper gastrointestinal surgery or who suffered from debilitating conditions likely to interfere with tissue healing.

Initially treatment was given for 4 weeks and followed by a check endoscopy. If healing had not taken place a further 4 week course of medication at the same dosage frequency was provided and a third endoscopy carried out 8 weeks after entry. Any cases not having healed at this stage were withdrawn and placed on alternative ulcer-healing drugs. Information on side effects was requested at each visit for repeat endoscopy. Blood for the estimation of bismuth levels was obtained at entry and repeated at 4 weeks. In those cases still on treatment a further sample was taken at 8 weeks.

\section{Results}

\section{Ulcer healing}

The results show that after 4 weeks of treatment 14 of 21 cases $(67 \%)(95 \%$ confidence limits $=43-85 \%)$ healed in the group given tablets four times daily and 18 of $25(72 \%)(95 \%$ confidence limits $=51-88 \%)$ among those receiving medication twice daily. Those who failed to heal at 4 weeks received a further course 
of identical treatment bringing the healing rates at 8 weeks to $17(81 \%)(95 \%$ confidence limits $=58-95 \%)$ in the QDS group and $23(92 \%)(95 \%$ confidence limits $=74-99 \%$ ) in the BD group. Two patients in the QDS group failed to attend for their final endoscopy at 8 weeks and for the purposes of analysis the healing rate of $81 \%$ is based on the assumption that neither of these two cases were healed.

Using the Chi square test no statistically significant difference exists between ulcer healing rates in the two groups at 4 weeks $(P=0.944)$ or at 8 weeks $(P=0.504)$ though numerically the trend may be in favour of the twice daily dosage.

\section{Bismuth levels}

Serum bismuth levels were measured in the first 30 patients enrolled in the trial. These consisted of 14 and 16 cases from the QDS and BD groups respectively. Mean bismuth levels at 4 and 8 weeks were $10 \mu \mathrm{g} / 1$ and $10 \mathrm{~g} / 1$ respectively for the group receiving TDB four times daily and $13 \mu \mathrm{g} / \mathrm{l}$ and $12 \mu \mathrm{g} / \mathrm{l}$ for those given TDB twice daily. The highest single concentration recorded was $30 \mu \mathrm{g} / 1$ in a patient after 4 weeks' treatment in the BD group. All measurements were well below the therapeutically acceptable upper limit of $50 \mu \mathrm{g} / 1$ (Hillemand et al., 1977).

\section{Side effects}

No clinically significant side effects were encountered. The commonest complaint was of a mild and temporary blackish discoloration of the tongue which occurred in 8 cases in the QDS group and 9 cases in the $B D$ group. No patient considered this an unacceptable problem and in no case was discontinuation of the medication required because of it. Other side effects reported were of an unpleasant lingering taste after chewing the tablets (one complaint from each group) and one instance of flatulent dyspepsia after the tablets in the BD group.

\section{Withdrawals}

Seven patients were withdrawn during the course of the trial, five of these being from the QDS group. Nos compliance with dosage requirements resulted in five withdrawals (four from the QDS and one from the BD group) while a further two cases (one from each group) needed urgent surgery, one for bleeding and the other for pyloric stenosis.

\section{Discussion}

This study shows TBD chewable tablets given twige daily to be as effective as the equivalent dose administ tered four times daily in the healing of duodenal ulcers. The rate of healing observed at 4 weeks $(72 \%)$ and 88 weeks $(92 \%)$ in the group given treatment twice da is comparable with that previously reported for TD (66\% at 4 weeks and $89 \%$ at 8 weeks) and cimetidize $(60 \%$ at 4 weeks and $85 \%$ at 8 weeks) (Martin et a 23 1981). No adverse effects peculiar to the twice dajy TDB regime were encountered.

These results are of some interest in relation to the proposed mode of action of TDB. It is generally suggested that this drug acts as a mucosal protectant but how this is achieved is unknown. Direct shielding of the ulcer surface from acid and peptic digestion ty adherence of the bismuth salt has been suggested Koo et al. (1982) who were able to show the adherence of bismuth to the surface of experimental gastric $\mathrm{gc}$ in rats by histochemical means but not macroscopisa ly. Staining was prominent only in animals killed $\bar{q}$ to 2 hours after ingestion of TDB and much less eviđe thereafter. The idea of a short-lived physical barrie over the ulcer surface producing the healing effect TDB is not appealing but may have some merit if the barrier is renewed four times daily as with conve tional dosage frequency. However, such a proposed mechanism of action seems much less likely when twice daily administration produces the same healin effect. If the bismuth attached to the ulcer surface is important then it probably does not act as a simpte mechanical barrier against acid and pepsin.

Other suggested modes of action for TDB include regenerative affect on the microvilli of duodena mucosal cells (Moshal et al., 1979) and the possibilit that TDB encourages the return of gastric muctors

Table I Patient details in those given TDB tablets four times daily (QDS group) or twice daily (BD group). Where appropriact mean values are presented followed by the range in brackets.

\begin{tabular}{|c|c|c|c|c|c|c|c|}
\hline & No. cases & Female & $\begin{array}{l}\text { Age } \\
(y)\end{array}$ & $\begin{array}{c}\text { Ulcer duration } \\
(y)\end{array}$ & $\begin{array}{l}\text { Duration present } \\
\text { relapse (months) }\end{array}$ & $\begin{array}{c}\text { Smoking } \\
\text { (cigs/day) }\end{array}$ & $\begin{array}{r}\text { Alcohol స్ } \\
\text { (drinks/we 麥) }\end{array}$ \\
\hline QDS group & 21 & 9 & $\begin{array}{c}48 \\
(19-75)\end{array}$ & $\begin{array}{c}3.7 \\
\left(0.5^{-15}\right)\end{array}$ & $\begin{array}{c}6 \\
(3-24)\end{array}$ & $\begin{array}{c}10 \\
(0-30)\end{array}$ & $\begin{array}{c}6.5 \stackrel{0}{\stackrel{2}{D}} \\
(0-50)\end{array}$ \\
\hline BD group & 25 & 4 & $\begin{array}{c}50 \\
(17-79)\end{array}$ & $\begin{array}{c}6.2 \\
(0.25-30)\end{array}$ & $\begin{array}{c}5.1 \\
(3-12)\end{array}$ & $\begin{array}{c}12 \\
(0-40)\end{array}$ & $\begin{array}{c}6.1) \\
(0-35) \frac{0}{0}\end{array}$ \\
\hline
\end{tabular}


towards a normal quality and quantity during ulcer healing. Such an effect has been demonstrated for gastric ulcer treated by TDB (Hollanders et al., 1983). How such actions are produced by the drug are entirely unclear and hence there are no theoretical reasons why a twice daily dosage should not be as effective as four times per day.

On the basis of our results it is concluded that TDB administered twice daily is an effective treatment for duodenal ulcer. This reduced frequency of administra-

\section{References}

HILLEMAND, P., PALLIERE, M., LAQUAIS, B. \& BOUVET, P. (1977). Traitment bismuthique et bismuthemie. Semaine des Hospitaux de Paris, 54, 1663.

HOLLANDERS, D., MORRISSEY, S.M. \& MEHTA, J. (1983). Mucus secretion in gastric ulcer patients treated with tripotassium dicitrato bismuthate. British Journal of Clinical Practice, 37, 12.

KOO, J., HO, J., LAM, S.K., WONG, J. \& ONG, G.B. (1982). Selective coating of gastric ulcer by tripotassium dicitrato bismuthate in the rat. Gastroenterology, 82, 864.

MARTIN, D.F., HOLLANDERS, D., MAY, S.J., RAVENSCROFT, M.M., TWEEDLE, D.E.F. \& MILLER, J.P. (1981). Difference in relapse rates of duodenal ulcer after healing with cimetidine or tripotassium dicitrato bismuthate. Lancet, $\mathbf{i}, 7$. tion, brings bismuth subcitrate therapy into line with the dosage frequency of other ulcer healing medicaments and is likely to increase both compliance with and patient acceptability of this drug.

\section{Acknowledgements}

We are grateful to Brocades (GB) Ltd. for supplying the trial materials and to Mrs M. Williamson for typing the manuscript.

MOSHAL, M.G., GREGORY, M.A. \& PILLAG, C. (1979). Does the duodenal cell ever return to normal. A comparison between treatment with cimetidine and DeNol. Scandinavian Journal of Gastroenterology, 14, Suppl. 54, 48.

MOSHAL, M.G., SPITAELS, J.M. \& KAHN, F. (1981). Tripotassium dicitrato bismuthate chewing tablets and cimetidine tablets in the treatment of duodenal ulcers. South African Medical Journal, 60, 420.

SHREEVE, D.R., KLASS, H.J. \& JONES, P.E. (1983). Comparison of cimetidine and tripotassium dicitrato bismuthate in healing and relapse of duodenal ulcers. Digestion, 28, 96.

VANTRUPPEN, G., RUTGEERTS, P., NROECKAERT, L. \& JANSSENS, J. (1980). Randomised, open controlled trial of colloidal bismuth subcitrate tablets and cimetidine in the treatment of duodenal ulcer. Gut, 21, 329. 